\title{
Research on Simulation and Analysis of Fire Emergency Decision Ming Zhao ${ }^{1, a}$, Zizuo Liu ${ }^{1, b}$ and Shoujin Wang ${ }^{1, c^{*}}$ \\ ${ }^{1}$ School of Information \& Control engineering, Shenyang Jianzhu University, Shenyang, China a1094301006@qq.com, ${ }^{b} 575920821 @ q q . c o m,{ }^{c}$ 23917240@qq.com
}

\section{Keywords: Villages and towns; Fire; Numerical simulation; Decision support}

\begin{abstract}
With the rapid development of rural economy in China, fire threat faced by villages and towns and the loss caused by fire also increase. At the same time, compared with city, in villages and towns, disaster relief facilities for fire emergency management are weak, and the decision support systems are lack. This paper established the rural fire simulation analysis system by using information technology, which can reconstruct the virtual fire environment and the disaster model based on visualization technology, and realize simulation of dynamic spread process of the fire. The system proposed a method to get the number of safety and economic indicators related to disaster decision-making, provided a reliable basis for emergency management for the prevention and control of fire in villages and towns.
\end{abstract}

\section{Introduction}

In recent years, with the improvement of rural economy and the development of people's living standards, under the promotion of the township enterprises, rural industrial structure has a diversified development trend. At the same time, because of the limitation of geographical environment, weak traffic rescue network, the traditional backward concept on infrastructure construction and attention on rescue other than prevention in villages and towns, the threat of fire is more serious, the disaster impact is wider, and reconstruction after disaster is more difficult. To strengthen the emergency management of rural emergencies, establish effective fire prevention and emergency management mode, has already become a major challenge [1].

With the development of information technology, in order to realize information management and decision support, the use of computer simulation and analysis on fire has become the development trend of fire prevention and rescue [2]. University of California designed and implemented a fire damage simulation model for Pola-Alto city [3]; Xu Yun of Tsinghua University studied on the hazard probability of city earthquake fire and city fire schedule and control system[4]; Xu Jiandong of China Earthquake Administration Institute constructed mathematical model of fire spread of city earthquake under the condition of complex system[5]; Wang Wenjun of Peking University studied rapid fire recognition and vehicle tracking of 119 city fire schedule and control system[6]. Although there are many research results in fire simulation, these studies are based on fire prevention, information management, digital simulation and analysis and evaluation of post disaster information in city[7-9]. At present, there is still no special research on villages and towns.

Therefore, in order to study fire simulation and analysis system for villages and towns, this paper adopts advanced ArcGIS technology based on B/S architecture, implementing fire simulation based on effective information management on villages and towns to provide visual information services and decision support for the town governments.

\section{System Design}

Design Principles. Main functions of rural fire simulation system include: establishment of village fire simulation model, to realize dynamic simulation of spread process of fire; establishment of information management model, to realize visualization management on disaster information, such as basic information and disaster lifeline facilities; establishment of emergency response model, to 
support emergency decision; visualization of the above models based on GIS technology[10-11]. The design idea of the whole system is shown in Fig. 1.

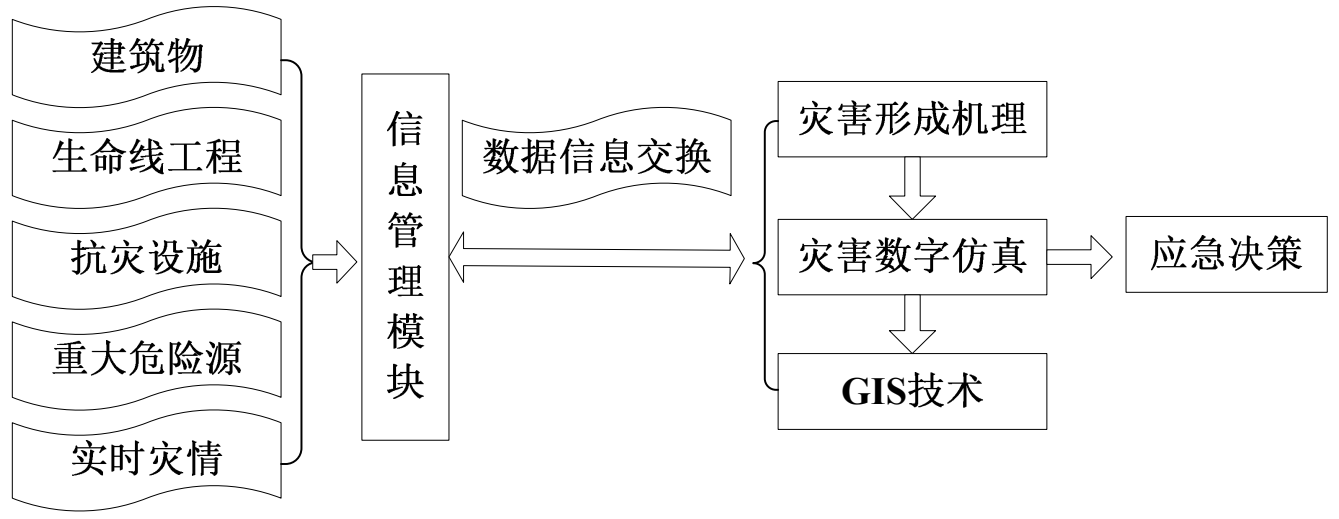

Figure 1. Design principles of the system

The modules of building, lifeline engineering, major hazard, disaster facilities and other information provide information support for fire simulation; fire formation mechanism is the basis of fire simulation theory; GIS technology is the core of digital fire simulation platform; fire simulation results are directly used to guide emergency decision-making and planning of security space.

System Flow. System simulation function can be divided into analysis of fire risk probability, fire spread simulation, fire emergency schedule and fire loss prediction. Because the operation parameters of each model are based on the results of other models, the system sets computation sequence and operation steps according to ire fighting schedule mode[12-13]. System model operation flow is shown in Fig. 2.

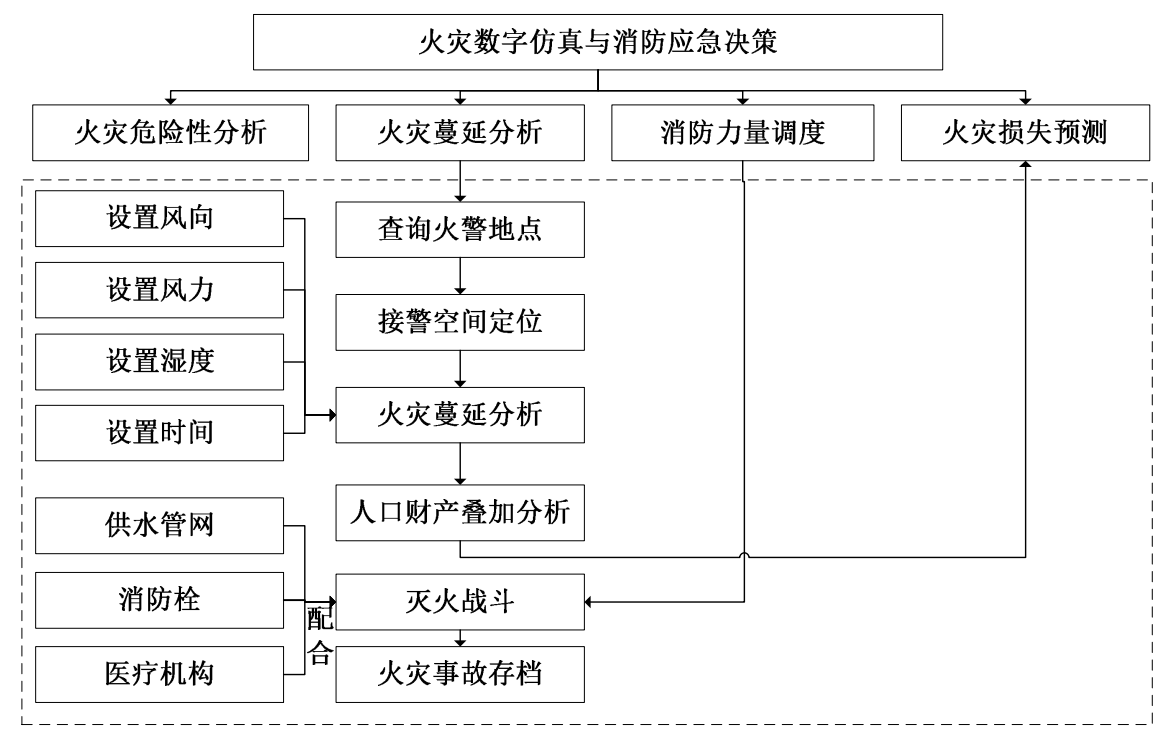

Figure 2. System flow

Architecture. The system adopts WebGIS architecture based on $\mathrm{B} / \mathrm{S}$, with the client using a standard Web browser to interact with the server. Based on the idea of component, the system is divided into reconfigurable components which can be expanded. In order to deal with the relevant parts of the business requirements better, system implementation is extended based on the $\mathrm{B} / \mathrm{S}$, using three layer models as the system structure.

The user layer uses the browser to interact with the system, and implemented with Ajax technology combined with HTML technology to achieve a graphical friendly interface, improve the user experience and facilitate the user to use the system functions. 
The middle layer is the core part of the system implemented by $\mathrm{C} \#$ language, with the characteristics of flexible data processing, applicable function and convenient to operate, ensuring system running speed and compatibility. The middle layer includes three sub layers, presentation, business and access. The presentation layer provides interface show to the browser; the business layer includes visual information query and management, fire risk analysis, fire spread analysis, loss prediction and archiving; access layer provides database access function, which enables the system to access attribute data and spatial map data.

The data layer mainly refers to the attribute database and spatial database, which are used to build fire basic information database, village and town spatial database, simulation model base, simulation algorithm base and the historical archives database and so on.

Development Technology. The system uses Visual Studio 2008 as the development platform, C\# as programming language, and ArcGIS Server 9.3.1 as GIS service platform. The database is managed by SQL Server 2005 with operating system Windows Server 2003 Enterprise Edition. The hardware platform is P5, with frequency 3.0Ghz, memory 4GB and hard disk 250GB.

\section{Simulation Method}

According to information of building, weather and environment, fire simulation model calculates the probability of single building fire; when fire takes place in a building, according to the position of fire and the current weather condition, calculates fire spread speed, according to which analysis on spread range is computed to provide decision support for rescue.

Fire Probability Analysis Model on Building. According to the current weather conditions, the fire probability of the single building is calculated.

\section{Input:}

Default attributes of the building: whether there is combustible material, combustible grade, etc., basic data attributes of the building from building dictionary table.

$P(M)$ : according to whether there is combustible material in the building, its value is set as 1 for yes 0 for no;

$P\left(F_{k} / M\right)$ : the effect of combustible material on fire.

Weather, season and environment effects, showed as $P(G)$.

\section{Calculation Formula:}

$$
\begin{aligned}
& P\left(R_{j}\right)=P(M) \times P\left(F_{k} / M\right) \times P(G) \\
& P\left(R_{j}\right) \text { is the probability of fire for building } \mathrm{j} . \\
& \text { Output: } P\left(R_{j}\right)
\end{aligned}
$$

Fire Spread Analysis Model.After the determine on the location of building on fire, the calculates fire spread range a specific period of time.

\section{Input:}

Coordinates of building on fire, spatial data of the building from the map.

Time of fire duration

Layer height of the building, basic attribute of the building, which is derived from the building dictionary.

Wind speed at the time of fire

\section{Calculation Formula:}

\section{Calculation of Fire Spread Speed}

$$
V=0.801 \times(3.6 U)^{1.1} \times B H
$$


$V$ is the fire spread speed, and the unit of it is $\mathrm{m} / \mathrm{s} ; U$ is the wind speed, and unit it is $\mathrm{m} / \mathrm{s} ; B H$ is layer height of the building, and the unit of it is $m$. This formula is based on the assumption that the fuel properties in the spreading area are homogeneous without considering the impact of slope.

Calculation of fire spread radius

$T$ is the duration of the fire.

$$
R=V \times T
$$

Calculation of distances to other buildings from fire point

$D_{j}=R_{e} \times \arccos \left[\sin \phi_{j} \sin \phi_{i} \cos \left(\lambda_{i}-\lambda_{j}\right)+\cos \phi_{j} \cos \phi_{i}\right] \times \pi / 180$

$D_{j}$ is the distance from building $\mathrm{j}$ to building $\mathrm{i}$ on fire. ${ }^{\phi_{j}}$ and ${ }^{\lambda_{j}}$ are longitude and latitude of building $\mathrm{j}$. $R_{e}$ is the radius of the earth. Note that to determine the longitude and latitude, follow principles: positive with east longitude, negative with west longitude, minus 90 with north latitude and plus 90 with south latitude.

Output: comparing between ${ }^{D_{j}}$ and V to determine the spread range of the fire.

\section{System Implementation}

Building Fire Probability Analysis and Display. After selecting the weather condition in the operation interface, the system automatically calculates the probability of fire risk of single building and displays the result as a list.

According to preliminary quantitative building fire risk probability, after specifying fire probability threshold, buildings of fire hazard are determined and displayed by visual map, the top of the interface displays a list of building attribute information whose fire probability exceeds the threshold, and the bottom of the interface displays the space information of those buildings highlighted in red.

Location of Fire Points and Information Display. On the operation interface, click the building on fire on the map, then the interface displays a list of attribute information of the building, with the map displaying spatial information of the building. At the same time, fire information related data can be input into fire information list underside.

Fire Spread Analysis and Display. On the operation interface, use drop-down list box to select fire to analyze, then input fire duration, click OK button, a list of buildings in the fire spreading range is displayed on the map in red highlighted.

\section{Conclusions}

Rural fire simulation and analysis system based on Web, can provide village government with effective management on infrastructure and disaster relief facilities, realize digital simulation on fire, so as to support disaster prevention, disaster response and disaster assessment as operational technology. The system also can support decision making based on spatial data, providing village manager with visual information service and decision support to avoid time delay and mistake in decision-making caused by objective environment and human factor, so that the loss on property and population is reduced to the minimum degree. The system is applied in a number of towns and villages of Liaoning Province and is well received, supporting the decision make on disaster relief facilities construction, simulation of high fire hazard management and fire simulation analysis.

\section{Acknowledgements}

Science and technology program of Liaoning(20170540767) 


\section{References}

[1] Yang Jiachun. Study on fire risk assessment system of villages and towns [D]. Master Thesis of Beijing University of Technology, 2008.

[2] Cong Beihua, Liao Guangxuan, Wei Yaxing. Computer simulation in the research of fire science and engineering application[J]. Journal of disaster prevention and mitigation engineering, 2003,23 (2): 63 - 69.

[3] Bryant P, Deenges GR, Samuels WB, et al. Fire Spread Computer Simulation of Urban Conflagrations[C]. In: Proceedings of the Multi Conference on the 1993 Simulation International Emergency Management and Engineering Conference, San Diego: SCS, 1993:149-154.

[4] Xie Xuyang, Ren Aizhu. Spread simulation system of fire post-earthquake in city[J]. Fire science and technology, 2003 (6): 460-462.

[5] Xu Jiandong, Wang Xinru, Lin Jiande, et al. A preliminary study on the spread of urban secondary earthquake fire based on GIS[J]. Seismic geology, 2002,24 (3): 445-452.

[6] Wang Wenjun, Wang Yuelong, Luo Yingwei, et al. Design and implementation of "119" fire control and schedule system based on GIS[J]. Computer Engineering, 2004, 30(5):9-11.

[7] Savsar M, Aleisa E. Simulation Modeling and Analysis of Fire Fighting Operations in the State of Kuwait[J]. International Journal of Information Systems \& Supply Chain Management, 2015, $8(2): 31-48$.

[8] Aleisa E, Savsar M. Response Time Analysis of Firefighting Operations Using Discrete Event Simulation[C]// Uksim-Amss, International Conference on Computer Modelling and Simulation. IEEE, 2014:330-334.

[9] Luo J, Cui Y, Li G. Study and Simulation Analysis for Dual-Drive Control Strategy of the Firefighting and Rescue Equipment[C]// International Conference on Advances in Mechanical Engineering and Industrial Informatics. 2015.

[10] Hall K A. The Effect of Computer-Based Simulation Training on Fire Ground Incident Commander Decision Making.[J]. Proquest Llc, 2010:145.

[11] Almer A, Schnabel T, Perko R, et al. Multi-Level Wild Land Fire Fighting Management Support System for an Optimized Guidance of Ground and Air Forces[C]// EGU General Assembly Conference. EGU General Assembly Conference Abstracts, 2016.

[12]Liu J, Cheng H. Simulation method of firefighting and rescue operation based on multi-Agent joint[J]. Jiangsu Daxue Xuebao, 2014, 35(5):564-570.

[13] Huang H, Tang L, Li J, et al. Simulation and visualization of forest fire growth in an integrated 3D virtual geographical environment - a preliminary study[C]// International Conference on Geoinformatics. IEEE, 2012:1-6. 